Check for updates

Cite this: RSC Adv., 2019, 9, 32712

Received 5th September 2019

Accepted 6th October 2019

DOI: $10.1039 / c 9 r a 07111 c$

rsc.li/rsc-advances

\section{First-principles investigation of the microscopic mechanism of the physical and chemical mixed adsorption of graphene on metal surfaces}

\begin{abstract}
Xin Zhang (iD) *ab and Shaoqing Wang ${ }^{a}$
The binding energy, bond length, projected density of states and differential charge density of graphenemetal interfaces are investigated using a first-principles method in which a single layer graphene is adsorbed on the low-index metal surfaces such as the (111), (110) and (100) surfaces. The bond length results show the graphene sheet has a different degree of buckling after graphene is adsorbed on the (110) and (100) surfaces of metals. The projected density of states and the differential charge density results confirm the adsorption of graphene on the $\mathrm{Ni}(111), \mathrm{Co}(111), \mathrm{Ni}(110), \mathrm{Co}(110)$ and $\mathrm{Cu}(110)$ surfaces is chemisorption due to the strong orbital coupling effect and the obvious charge accumulation between the carbon and metal atoms, while the adsorption of graphene on the $\mathrm{Cu}(111)$ surface is physical adsorption owing to the absence of the orbital coupling effect and the charge accumulation between the carbon and $\mathrm{Cu}$ atoms. Interestingly, the adsorption of graphene on the (100) surface of $\mathrm{Ni}, \mathrm{Co}$ and $\mathrm{Cu}$ is all physical and chemical mixed adsorption because there are the strong orbital coupling effect and the apparent charge accumulation between the carbon and metal atoms in some parts of these surfaces while there are almost no orbital coupling effects and charge accumulation between the carbon and metal atoms in other parts.
\end{abstract}

\section{Introduction}

Graphene, a two-dimensional single atomic layer structure which is composed of $\mathrm{sp}^{2}$ carbon atoms arranged in a honeycomb crystal lattice, has attracted tremendous attention and research interest since it was prepared successfully by mechanical exfoliation from graphite in 2004. ${ }^{\mathbf{1 , 2}}$ Graphene essentially displays many intriguing and peculiar properties such as a theoretically large surface area $\left(\sim 2630 \mathrm{~m}^{2} \mathrm{~g}^{-1}\right),{ }^{3}$ high room temperature charge carrier mobility $\left(\sim 1 \times 10^{5} \mathrm{~cm}^{2} \mathrm{~V}^{-1}\right.$ $\left.\mathrm{s}^{-1}\right),{ }^{4}$ excellent mechanical properties ${ }^{5}$ including a Young's modulus of 1.0 TPa and fracture strength of $125 \mathrm{GPa}$, high thermal conductivity ( 2000 to $\left.5000 \mathrm{~W} \mathrm{~m}^{-1} \mathrm{~K}^{-1}\right),{ }^{6,7}$ capacity to sustain large electrical current density $\left(10^{8} \mathrm{~A} \mathrm{~cm}^{-2}\right)^{8}$ and so on. These unique properties of graphene make it a hot research topic in the field of materials science, and endow graphenebased composites with better properties. ${ }^{9}$ Graphene-metal composites are an important part of the research on graphenebased composites, mainly including graphene-loaded metal nanoparticle composites and graphene-reinforced metal matrix composites. Graphene-loaded metal nanoparticle composites utilize graphene as the carrier to load metal nanoparticles in

${ }^{a}$ Shenyang National Laboratory for Materials Science, Institute of Metal Research, Chinese Academy of Sciences, 110016 Shenyang, Liaoning, China. E-mail: xzhang17b@imr.ac.cn

${ }^{b}$ School of Materials Science and Engineering, University of Science and Technology of China, 110016 Shenyang, Liaoning, China order to enhance the activity and dispersion of nanoparticles, which are applied in a broad range of fields such as catalysis, ${ }^{10-12}$ sensors, ${ }^{13,14}$ spectroscopy ${ }^{\mathbf{1 5 , 1 6}}$ and so on. Graphenereinforced metal matrix composites incorporate graphene sheets into the metal matrix, which can greatly enhance mechanical properties of metal materials without affecting or even improving the thermal and electrical properties of materials. ${ }^{17-19}$ Obviously, the interactions between graphene and metals will play a crucial role in the properties of graphenebased composites. Therefore, it is essential to study the interactions between graphene and different metal surfaces. There have been numerous experimental and theoretical studies on graphene contacted to metals such as $\mathrm{Ni}, \mathrm{Co}, \mathrm{Ru}, \mathrm{Rh}, \mathrm{Pd}, \mathrm{Ir}, \mathrm{Pt}$ and $\mathrm{Cu}^{20-37}$ Experimental studies about the growth of graphene on metal close-packed surface such as Ni(111), $\mathrm{Cu}(111)$ and $\mathrm{Ru}(0001)$ rank first. ${ }^{38-41}$ Secondly, experimental studies about the growth of graphene on other low-index metal surfaces such as $\mathrm{Ni}(100), \mathrm{Rh}(100)$ and $\mathrm{Pt}(110)$ have also been reported. ${ }^{\mathbf{4 2 - 4 4}}$ However, theoretical studies on the interfaces between graphene and metals mainly focus on the metal close-packed surface such as $\mathrm{Ni}(111), \mathrm{Co}(111), \mathrm{Cu}(111)$ and so on. ${ }^{28-37}$ In 2018, Mafra et al. not only investigated different growth mechanisms of graphene on Ni(100), (110) and (111) surface by optical microscopy, Raman spectroscopy and optical transmission but also provided an atomistic model of the processes involved to support the experimental results by density functional theory calculations. ${ }^{43}$ Theoretical studies on the 
adsorption of graphene on the (110) and (100) surfaces of other metals except $\mathrm{Ni}$ are rarely reported.

The (111), (110) and (100) surfaces are the most basic and important low-index metal surfaces. In particular, the closepacked structure of the (111) surface of $\mathrm{Ni}$, $\mathrm{Co}$ and $\mathrm{Cu}$ has been commonly used to make graphene-metal contacts owing to their structural resemblance. The difference is the adsorption of graphene on the (111) surface of $\mathrm{Ni}$ and $\mathrm{Co}$ is chemisorption while the adsorption of graphene on the $\mathrm{Cu}(111)$ surface is physical adsorption. However, the lack of hexagonal symmetry of (110) and (100) surfaces results in less theoretical studies on graphene-metal contacts. Therefore, in this work, in order to explore the adsorption mechanism of graphene on metal surfaces, taking $\mathrm{Ni}$, Co and $\mathrm{Cu}$ as examples, the interfaces between graphene and low-index metal surfaces such as (111), (110) and (100) surfaces are investigated by using firstprinciples calculations at the level of density functional theory (DFT). The results obtained by the present study are not only expected to explain the adsorption mechanism of graphene on the metal surfaces, but also to provide help for the research of graphene-based composites and carbon nanomaterials.

\section{DFT calculations}

Density function theory (DFT) calculations based on plane-wave basis sets of $500 \mathrm{eV}$ cut-off energy were performed with the Vienna $a b$ initio simulation package (VASP). ${ }^{44,45}$ The local density approximation (LDA ${ }^{46}$ was used to describe the exchange correlation effect because of the better performance of LDA compared with the generalized gradient approximation (GGA) in predicting binding behaviour for interfaces between carbon nanostructures and metals. ${ }^{26,47}$ The projectoraugmented wave (PAW) was used to describe the electron-ion interactions. ${ }^{48,49}$ Metal surface is constructed in a supercell as a finite number of layers of metal plus a region of vacuum repeated periodically in the direction perpendicular to the layers. The supercell used to model the graphene-metal interface is constructed from a slab consisting of six layers of metal atoms, with a graphene layer adsorbed from the top side of the slab and a vacuum region of $15 \AA$. Considering that the metal substrate is usually much thicker than the upper layer film and it is usually the film that trends to match the lattice constant (LC) of the metal substrate in experiment, ${ }^{50,51}$ the lattice constant of metal unit cells is fixed to construct the interface supercell. Therefore, taking the metal $\mathrm{Ni}$ as an example, the $4 \times$ 4 graphene unit cell is adjusted to the $4 \times 4$ unit cell of $\mathrm{Ni}(111)$ surface as shown in Fig. 1 (a); the $2 \times 4 \sqrt{3}$ graphene unit cell is adjusted to the $2 \times 5 \sqrt{2}$ unit cell of $\mathrm{Ni}(110)$ surface as shown in Fig. 1(b); the $2 \times 4 \sqrt{3}$ graphene unit cell is adjusted to the $2 \times 7$ unit cell of $\mathrm{Ni}(100)$ surface as shown in Fig. 1(c); while for graphene- $\mathrm{Cu}(100)$ interface, the $2 \times 3 \sqrt{3}$ graphene unit cell is adjusted to the $2 \times 5$ unit cell of $\mathrm{Cu}(100)$ surface in order to build a better matching model as shown in Fig. 1(d). The approximation made by the matching procedure is reasonable since the mismatch with the lattice constant of the graphene sheet is only $0.629-3.825 \%$, as seen in Table 1 . A dipole

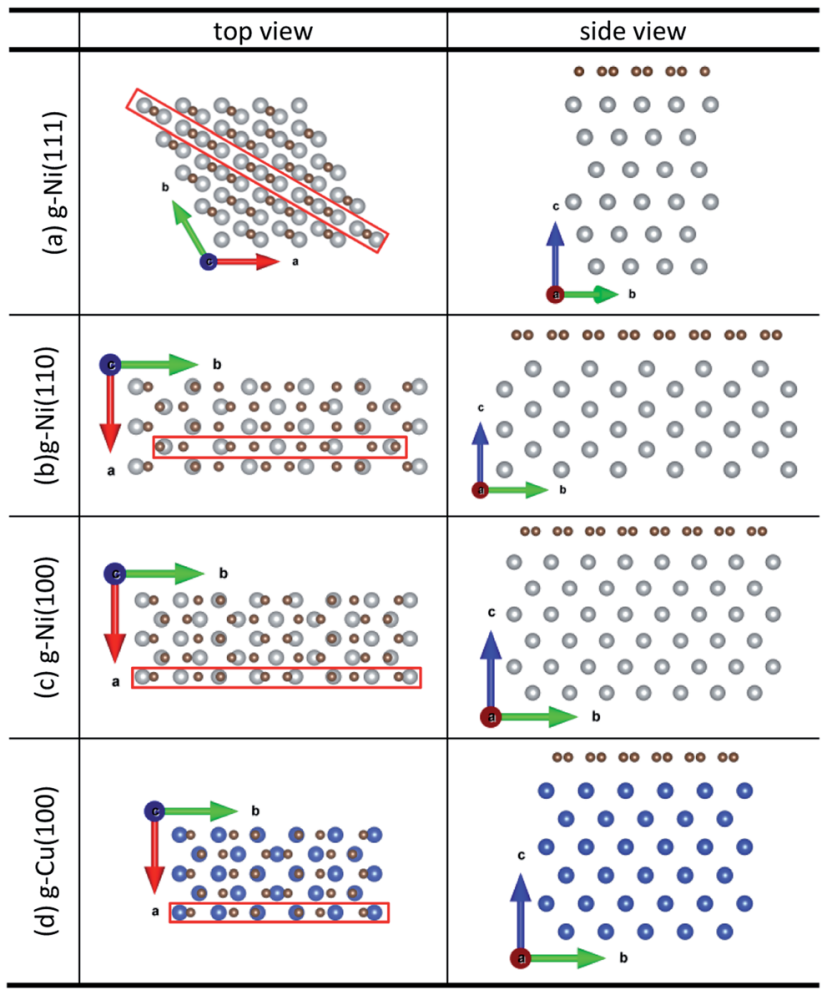

Fig. 1 The top and side views of initial configurations ((a) graphene$\mathrm{Ni}(111)$, (b) graphene-Ni(110), (c) graphene-Ni(100) and (d) graphene$\mathrm{Cu}(100))$.

correction is applied to avoid spurious interactions between periodic images of the slab. ${ }^{52}$ The electronic self-convergence criterion is set to $1.0 \times 10^{-5} \mathrm{eV}$ and the forces on all the atoms are converged to within $0.01 \mathrm{eV}^{-1}$ with respect to ionic relaxation.

\section{Results and discussions}

\section{Graphene-metal binding}

The average equilibrium interfacial distance $\left(d_{\mathrm{eq}}\right)$, the binding energy $\left(E_{\mathrm{b}}\right)$ for graphene adsorbed on the (111), (110) and (100) surfaces of metals and the maximum buckling on the graphene layer studied in this paper are listed in Table 1. It can be seen our calculated results are slightly different from those reported in the literatures, ${ }^{28,43}$ but the overall trend is basically the same. We believe the difference in results may be due to the following reasons. Firstly, the supercells we constructed are larger than those in the literature ${ }^{28,53}$ when graphene is adsorbed on the (111) surface of metals. Besides, the adsorption configuration of graphene on the (111) surface of metals is different from that in the literature, ${ }^{28}$ but this configuration has been confirmed by experiments. ${ }^{34}$ The binding energy in the paper was calculated by underlying formula

$$
E_{\mathrm{b}}=\left(E_{\text {graphene }}+E_{\text {metal surface }}\right)-E_{\text {graphene-metal interface }}
$$

where, $E_{\text {graphene }}, E_{\text {metal surface }}$ and $E_{\text {graphene-metal interface }}$ represent the total energy of the bare slab, the isolated graphene, and the 
Table 1 The calculated lattice constant of graphene and metal supercell $\left(a_{\mathrm{g}}, b_{\mathrm{g}}\right.$ and $\left.a_{\mathrm{m}}, b_{\mathrm{m}}\right)$, lattice strain of graphene (a\% and $\left.b \%\right)$, calculated average equilibrium interfacial distance $\left(d_{\text {eq }}\right)$, binding energy $\left(E_{\mathrm{b}}\right)$ and the maximum buckling on the graphene layer are listed

\begin{tabular}{|c|c|c|c|c|c|c|c|c|c|}
\hline & $\mathrm{g}-\mathrm{Ni}(111)$ & $\mathrm{g}-\mathrm{Co}(111)$ & $\mathrm{g}-\mathrm{Cu}(111)$ & $\mathrm{g}-\mathrm{Ni}(110)$ & $\mathrm{g}-\mathrm{Co}(110)$ & $\mathrm{g}-\mathrm{Cu}(110)$ & $\mathrm{g}-\mathrm{Ni}(100)$ & $\mathrm{g}-\mathrm{Co}(100)$ & $\mathrm{g}-\mathrm{Cu}(100)$ \\
\hline$a_{\mathrm{g}}(\stackrel{\mathrm{A}}{0})$ & 9.784 & 9.784 & 9.784 & 4.892 & 4.892 & 4.892 & 4.892 & 4.892 & 4.892 \\
\hline$b_{\mathrm{g}}(\AA)$ & 9.784 & 9.784 & 9.784 & 16.947 & 16.947 & 16.947 & 16.947 & 16.947 & 12.710 \\
\hline$b_{\mathrm{m}}(\AA)$ & 9.666 & 9.527 & 9.968 & 17.086 & 16.841 & 17.621 & 16.915 & 16.672 & 12.460 \\
\hline$a \%$ & 1.221 & 2.698 & -1.846 & 1.221 & 2.698 & -1.846 & 1.221 & 2.698 & -1.846 \\
\hline$b \%$ & 1.221 & 2.698 & -1.846 & -0.814 & 0.629 & -3.825 & 0.189 & 1.649 & 2.006 \\
\hline$E_{\mathrm{b}}(\mathrm{eV}$ per $\mathrm{C})$ & 0.135 & 0.259 & 0.022 & 0.178 & 0.221 & 0.017 & 0.175 & 0.162 & 0.028 \\
\hline$E_{\mathrm{b}}^{\text {Ref }}($ eV per C) & $0.125^{a}$ & $0.160^{a}$ & $0.033^{a}$ & $0.209^{b}$ & - & - & $0.180^{b}$ & - & - \\
\hline Buckling (̊) & 0.0010 & 0.0102 & 0.0006 & 0.2016 & 0.3694 & 0.1192 & 1.0178 & 1.2743 & 0.8924 \\
\hline Buckling $^{\text {Ref }}(\AA)$ & $0.00^{a}$ & - & - & $0.29^{b}$ & - & - & $0.69^{b}$ & - & - \\
\hline
\end{tabular}

adsorption system, respectively. According to the definition, a positive $E_{\mathrm{b}}$ indicates the adsorption system should be stable. Buckling is defined as the coordinate difference of carbon atoms along the $z$ direction.

In our calculations, all graphene-metal interface models can be confirmed to be stable according to the definition of the binding energy. All the initial configurations are shown in Fig. 1. When graphene is adsorbed on the (111) surface of metals, the average equilibrium interfacial distance $\left(d_{\text {eq }}\right)$ and the binding energy $\left(E_{\mathrm{b}}\right)$ show the adsorption types of graphene on the (111) surface of metals can be divided into chemisorption and physical adsorption according to the literature. ${ }^{27}$ To be more specific, when $d_{\text {eq }}$ is less than $2.3 \AA$ and $E_{\mathrm{b}}$ is greater than $0.1 \mathrm{eV}$ per $\mathrm{C}$, the adsorption of graphene on the (111) surface of metals is chemisorption, while $d_{\mathrm{eq}}$ is greater than $3 \AA$ and $E_{\mathrm{b}}$ is less than $0.04 \mathrm{eV}$ per $\mathrm{C}$, the adsorption of graphene on the (111) surface of metals is physical adsorption. Combining the above criterion of adsorption type and our calculation results, it can be found the adsorption of graphene on the (111) surface of $\mathrm{Ni}$ and Co is chemisorption, while the adsorption of graphene on $\mathrm{Cu}(111)$ surface is physical adsorption. However, for graphene adsorbed on the (110) surface of metals, the average equilibrium interfacial distances are less than $2.3 \AA$, the binding energies of the graphene-Ni(110) interface and the graphene-Co(110) interface are greater than $0.1 \mathrm{eV}$ per $\mathrm{C}$ while the binding energy of the graphene- $\mathrm{Cu}(110)$ interface is less than $0.04 \mathrm{eV}$ per C. Unlike graphene adsorbed on the (111) surface of metals, the graphene sheet shows a certain degree of buckling. Therefore, the adsorption type of graphene on the (110) surface of metals needs to be further investigated. In terms of graphene adsorbed on the (100) surface of $\mathrm{Ni}$ and $\mathrm{Co}$, the average equilibrium interfacial distances are less than $2.3 \AA$ and the binding energies are 0.175 and $0.162 \mathrm{eV}$ per C, respectively. Notably, when graphene is adsorbed on $\mathrm{Cu}(100)$ surface, the average equilibrium interfacial distance is more than $2.3 \AA$ but less than $3 \AA$, and the binding energy is still less than $0.04 \mathrm{eV}$ per $\mathrm{C}$. However, the adsorption type of graphene on the (100) surface of metals also needs to be further investigated because the graphene sheet has a greater degree of buckling after graphene is adsorbed on the (100) surface. In conclusion, it is unreasonable to analyse the adsorption types of graphene on the (110) and (100) surfaces of metals by combining the binding energy and the average equilibrium interfacial distance due to no consideration for the buckling on the graphene sheet. In order to determine the adsorption types of graphene on different surfaces of $\mathrm{Ni}$, Co and $\mathrm{Cu}$ more accurately, the bond lengths $(r)$ between carbon and metal atoms at the interface can be used as a new criterion since the adsorption types of graphene on the (111) surface of $\mathrm{Ni}$, $\mathrm{Co}$ and $\mathrm{Cu}$ can be determined. And the bond length $(r)$ analysis will be discussed in the following paragraphs.

\section{Bond length analysis}

The initial configurations were constructed by matching graphene to metal surfaces as shown in Fig. 1. The relative positions and the bond lengths $(r)$ of carbon and metal atoms have changed to achieve the lowest energy state after graphene is adsorbed on metal surfaces. Local configurations are selected as the research object in order to better observe and compare the relative positions and the bond lengths $(r)$ between carbon and metal atoms. It should be noted that local configurations are taken from the red line frame areas in Fig. 1. The top and side views of local configurations induced by the adsorption of graphene on the (111) surface of metals are shown in Fig. 2. The top and side views show the relative positions of carbon and metal atoms have changed slightly after optimization. The bond lengths $(r)$ between carbon and metal atoms induced by the adsorption of graphene on the (111) surface of $\mathrm{Ni}$, Co and $\mathrm{Cu}$ are shown in Table 2. Therefore, the new criterion for adsorption types of graphene on $\mathrm{Ni}$, Co and Cu surfaces is as follows. When the bond lengths $(r)$ between carbon and metal atoms at the interface are about $2.2 \AA$, indicating carbon atoms can form covalent bonds with metal atoms, that's to say, the adsorption of graphene on $\mathrm{Ni}$, Co and $\mathrm{Cu}$ surfaces is chemisorption, while the bond lengths $(r)$ between carbon and metal atoms are larger 


\begin{tabular}{|c|c|c|c|c|c|c|c|c|c|}
\hline \multirow{3}{*}{ م. } & \multicolumn{5}{|c|}{ top view } & \multicolumn{4}{|c|}{ side view } \\
\hline & (a) & $\infty \infty$ & $\infty$ & $\infty$ & $\infty$ & $\begin{array}{c}0 \\
0\end{array}$ & $\begin{array}{c}00 \\
0\end{array}$ & $\begin{array}{c}00 \\
0\end{array}$ & $\begin{array}{c}0 \\
0\end{array}$ \\
\hline & (a') & $\infty 0$ & $\infty$ & $\infty \infty$ & $\infty$ & $\begin{array}{c}12 \\
0 \\
0 \\
1\end{array}$ & $\begin{array}{c}3.4 \\
0.0 \\
0 \\
2\end{array}$ & $\begin{array}{c}56 \\
0 \\
0 \\
0 \\
3\end{array}$ & $\begin{array}{c}78 \\
0 \\
0 \\
4\end{array}$ \\
\hline$\widehat{\exists}$ & (b) & $\infty$ & $\infty$ & $\infty$ & $\infty$ & $\begin{array}{l}\circ 0 \\
0\end{array}$ & $\begin{array}{l}00 \\
\bullet\end{array}$ & $\begin{array}{c}0 \\
\bullet\end{array}$ & $\begin{array}{l}\circ 0 \\
\bullet\end{array}$ \\
\hline مَذِ & (b') & $\infty$ & $\infty$ & $\infty$ & $\infty$ & $\begin{array}{l}122 \\
0 \\
0 \\
1\end{array}$ & $\begin{array}{l}34 \\
0 \\
0 \\
0 \\
2\end{array}$ & $\begin{array}{c}56 \\
\circ \\
\circ \\
0 \\
3\end{array}$ & $\begin{array}{l}78 \\
\circ \\
0\end{array}$ \\
\hline$\widehat{\exists}$ & (c) & $\infty \infty$ & $\infty$ & $\infty$ & $\infty$ & $\begin{array}{l}00 \\
\circ\end{array}$ & & 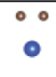 & $\because$ \\
\hline  & (c') & $\infty$ & $\infty$ & $\infty$ & $\infty$ & $\begin{array}{l}12 \\
0 \\
0 \\
1\end{array}$ & $\begin{array}{l}34 \\
30 \\
0 \\
2\end{array}$ & $\begin{array}{l}50 \\
5 \\
\circ \\
0 \\
0 \\
3\end{array}$ & 78 \\
\hline
\end{tabular}

Fig. 2 The top and side views of local configurations before ((a), (b) and $(c))$ and after $\left(\left(a^{\prime}\right),\left(b^{\prime}\right)\right.$ and $\left.\left(c^{\prime}\right)\right)$ the adsorption of graphene on the (111) surface of $\mathrm{Ni}, \mathrm{Co}$ and $\mathrm{Cu}$.

than $3 \AA$, indicating carbon atoms don't form covalent bonds with metal atoms, that's to say, the adsorption of graphene on $\mathrm{Ni}, \mathrm{Co}$ and $\mathrm{Cu}$ surfaces is physical adsorption.

Unlike graphene adsorbed on the (111) surface of $\mathrm{Ni}$, Co and $\mathrm{Cu}$, the graphene sheet shows a certain of buckling after graphene is adsorbed on the (110) surface of metals from the side views as shown in Fig. 3. Table 3 gives the bond lengths $(r)$ of carbon and metal atoms induced by the adsorption of graphene on the (110) surface of metals. The maximum and minimum bond lengths $(r)$ between carbon and $\mathrm{Ni}$ atoms are $2.357 \AA$ and $2.009 \AA$, respectively. And the maximum and minimum bond lengths $(r)$ between carbon and Co atoms are $2.398 \AA$ and 2.039 $\AA$, respectively. According to the new criterion mentioned above, it is known that the adsorption of graphene on the (110) surface of $\mathrm{Ni}$ and $\mathrm{Co}$ is chemisorption. However, for the graphene$\mathrm{Cu}(110)$ interface, the minimum bond length $(r)$ between carbon and $\mathrm{Cu}$ atoms is $2.218 \AA$, which is very close to $2.2 \AA$, while the maximum bond length $(r)$ between carbon and $\mathrm{Cu}$ atoms is $2.770 \AA$, which is slightly larger than $2.2 \AA$, but less than $3 \AA$. In general, the adsorption of graphene on $\mathrm{Cu}(110)$ surface is also chemisorption, but the interaction between carbon and $\mathrm{Cu}$ atoms is slightly weaker than that between carbon and $\mathrm{Ni}$ (or $\mathrm{Co}$ ) atoms.

Table 2 The bond lengths of carbon and metal atoms induced by the adsorption of graphene on the (111) surface of $\mathrm{Ni}, \mathrm{Co}$ and $\mathrm{Cu}$

\begin{tabular}{llll}
\hline$r(\AA)$ & $\mathrm{C}-\mathrm{Ni}(111)$ & $\mathrm{C}-\mathrm{Co}(111)$ & $\mathrm{C}-\mathrm{Cu}(111)$ \\
\hline$r_{1-1}$ & 2.116 & 2.068 & 3.043 \\
$r_{2-1}$ & 2.149 & 2.117 & 3.152 \\
$r_{3-2}$ & 2.116 & 2.068 & 3.043 \\
$r_{4-2}$ & 2.149 & 2.117 & 3.152 \\
$r_{5-3}$ & 2.116 & 2.068 & 3.043 \\
$r_{6-3}$ & 2.149 & 2.117 & 3.152 \\
$r_{7-4}$ & 2.116 & 2.068 & 3.043 \\
$r_{8-4}$ & 2.149 & 2.117 & 3.152
\end{tabular}

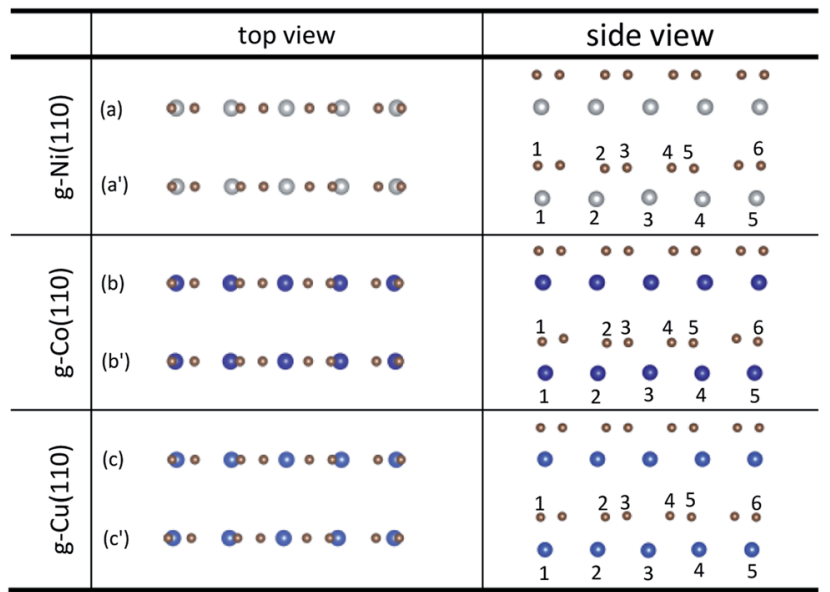

Fig. 3 The top and side views of local configurations before ((a), (b) and $(c))$ and after $\left(\left(a^{\prime}\right),\left(b^{\prime}\right)\right.$ and $\left.\left(c^{\prime}\right)\right)$ the adsorption of graphene on the (110) surface of $\mathrm{Ni}, \mathrm{Co}$ and $\mathrm{Cu}$.

An interesting phenomenon is that the graphene sheet shows a large of buckling after graphene is adsorbed on the (100) surface of $\mathrm{Ni}, \mathrm{Co}$ and $\mathrm{Cu}$ from the side views as shown in Fig. 4. In addition, there are obvious changes in the relative positions of carbon and $\mathrm{Ni}$ atoms observed from the top views as shown in Fig. 4. Table 4 shows significant changes in the bond lengths $(r)$ of carbon and metal atoms after optimization. The bond lengths $(r)$ of majority carbon and Ni atoms are less than $2.2 \AA$, and the bond lengths $(r)$ of minority carbon and $\mathrm{Ni}$ atoms are larger than $3 \AA$. Similarly, the bond lengths $(r)$ of majority carbon and Co atoms are about $2.2 \AA$, and the bond lengths $(r)$ of minority carbon and Co atoms are larger than $3 \AA$. According to the new criterion mentioned above, it can be concluded that the adsorption of graphene on the (100) surface of $\mathrm{Ni}$ and $\mathrm{Co}$ is physical and chemical mixed adsorption. Unlike the graphene-Ni(100) interface and the graphene- $\mathrm{Co}(100)$ interface, the bond lengths $(r)$ of minority carbon and $\mathrm{Cu}$ atoms are about $2.2 \AA$, and the bond lengths of some carbon and $\mathrm{Cu}$ atoms are close to $3 \AA$ while the bond lengths $(r)$ of other carbon and $\mathrm{Cu}$ atoms are larger than $3 \AA$, which indicates the interactions between carbon and $\mathrm{Cu}$ atoms are slightly weaker than those between carbon and $\mathrm{Ni}$ (or $\mathrm{Co}$ ) atoms. That's to say, the adsorption of graphene on the $\mathrm{Cu}(100)$ surface is the coexistence of physical adsorption and weak chemisorption. In other words, the adsorption of graphene on the (100) surface of Ni, Co and $\mathrm{Cu}$ is all physical and chemical mixed adsorption.

Table 3 The bond lengths of carbon and metal atoms induced by the adsorption of graphene on the (110) surface of $\mathrm{Ni}, \mathrm{Co}$ and $\mathrm{Cu}$

\begin{tabular}{llll}
\hline$r(\AA)$ & $\mathrm{C}-\mathrm{Ni}(110)$ & $\mathrm{C}-\mathrm{Co}(110)$ & $\mathrm{C}-\mathrm{Cu}(110)$ \\
\hline$r_{1-1}$ & 2.078 & 2.039 & 2.218 \\
$r_{2-2}$ & 2.009 & 2.040 & 2.270 \\
$r_{3-3}$ & 2.357 & 2.398 & 2.770 \\
$r_{4-3}$ & 2.357 & 2.398 & 2.770 \\
$r_{5-4}$ & 2.009 & 2.040 & 2.270 \\
$r_{6-5}$ & 2.078 & 2.039 & 2.218
\end{tabular}




\begin{tabular}{|c|c|c|}
\hline & top view & side view \\
\hline 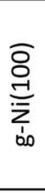 & 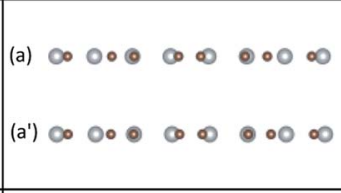 & $\begin{array}{cccccccc}0 & 0 & \circ & \circ & 0 & 0 & 0 & 0 \\
\circ & 0 & 0 & 0 & 0 & 0 & 0 & \circ \\
1 & & & & & & & \\
1 & 2 & 3 & 4 & 5 & 6 & 7 & 8 \\
& 0 & 0 & 0 & 0 & 0 & 0 & 0 \\
0 & 0 & 0 & 0 & 0 & 0 & 0 & 0 \\
1 & 2 & 3 & 4 & 5 & 6 & 7 & 8 \\
\end{array}$ \\
\hline 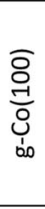 & $\begin{array}{l}\text { (b) } \infty \bullet \bullet \bullet \bullet \bullet \bullet \bullet \infty \\
\text { (b') } \bullet \bullet \bullet \bullet \bullet \bullet \bullet \bullet \bullet\end{array}$ & 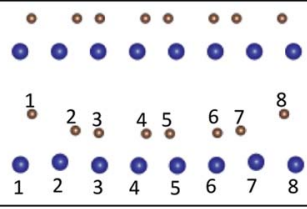 \\
\hline 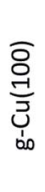 & $\begin{array}{l}\text { (c) } \quad \infty \bullet \bullet \bullet \bullet \infty \\
\text { (c) } \infty \odot \bullet \bullet \bullet \bullet \bullet\end{array}$ & 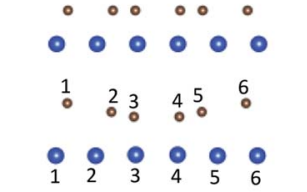 \\
\hline
\end{tabular}

Fig. 4 The top and side views of local configurations before ((a), (b) and $(c))$ and after $\left(\left(a^{\prime}\right),\left(b^{\prime}\right)\right.$ and $\left.\left(c^{\prime}\right)\right)$ the adsorption of graphene on the (100) surface of $\mathrm{Ni}, \mathrm{Co}$ and $\mathrm{Cu}$.

According to the geometric analysis above, the adsorption types of graphene on the metal surfaces are initially determined. Chemisorption process will not only have structural changes, such as the bond lengths $(r)$ and the relative positions between the carbon and metal atoms, but also have chemical changes, such as the coupling effect between atomic orbitals and charge accumulation between atoms. Therefore, in order to further verify adsorption types of graphene on the metal surfaces, we calculated the projected density of states (PDOS) and the differential charge density in the following paragraphs, respectively.

\section{Projected density of states (PDOS)}

The different interactions between graphene and the metal surfaces mainly arise from the different properties of metals. Ni atom $\left(3 \mathrm{~d}^{8} 4 \mathrm{~s}^{2}\right)$ and Co atom $\left(3 \mathrm{~d}^{7} 4 \mathrm{~s}^{2}\right)$ have open $\mathrm{d}$-shell with two and three unpaired electrons, respectively, while $\mathrm{Cu}$ atom $\left(3 \mathrm{~d}^{10} 4 \mathrm{~s}^{1}\right)$ has fully filled d-orbital and half-filled s-orbital, which means $\mathrm{Cu}$ atom has only one unpaired electron. Therefore, the interactions between graphene and $\mathrm{Ni}$ (or $\mathrm{Co}$ ) are stronger. Further investigation of the binding mechanism for graphenemetal interfaces was carried out by analysing the projected density of states (PDOS). Notably, as is known to all, the electronic states of graphene become obviously spin-polarized after it is adsorbed on the different surfaces of Ni and Co. Here, the present study only gives the PDOS of spin-up states in order to simplify the analysis. Fig. 5-7 show the projected densities of states of carbon and metal atoms at the interface before and after graphene is adsorbed on different metal surfaces, respectively. According to the degree of orbital coupling effect, the adsorption types of graphene on $\mathrm{Ni}$, Co and $\mathrm{Cu}$ surfaces can be divided into chemisorption, physical adsorption and physical and chemical mixed adsorption.

There exists the strong orbital coupling effect between the carbon and metal atoms after graphene is adsorbed on the
$\mathrm{Ni}(111), \mathrm{Co}(111), \mathrm{Ni}(110), \mathrm{Co}(110)$ and $\mathrm{Cu}(110)$ surfaces, that is to say, the adsorption of graphene on these metal surfaces is chemisorption. In more detail, for the graphene-Ni(111) interface, many overlapping peaks between the C- $\mathrm{p}_{z}$ orbital and the $\mathrm{Ni}-\mathrm{d}_{z^{2}}$ orbital are found in the energy range from -6 to $-4.5 \mathrm{eV}$, -4 to $-2 \mathrm{eV}$ and -1 to $0 \mathrm{eV}$ after graphene is adsorbed on the $\mathrm{Ni}(111)$ surface as shown in Fig. 5( $\left.\mathrm{a}^{\prime}\right)$, which shows the formation of covalent bonds between the C- $\mathrm{p}_{z}$ orbital and the Ni- $\mathrm{d}_{z^{2}}$ orbital. Still, the electron occupied states of the $\mathrm{Ni}-\mathrm{d}_{z^{2}}$ orbital increase significantly above the Fermi energy. Similarly, in the case of the graphene-Co(111) interface, the same conclusions can be drawn according to the projected density of states results in Fig. $5\left(b^{\prime}\right)$. After graphene is adsorbed on the Ni(110) surface, for carbon and $\mathrm{Ni}$ atoms near the configuration edge, many overlapping peaks in the energy range from -5 to $-3.5 \mathrm{eV},-3$ to $-1 \mathrm{eV}$, and -0.5 to $0 \mathrm{eV}$ are found between the C- $\mathrm{p}_{z}$ orbital and the Ni- $\mathrm{d}_{z^{2}}$ orbital as shown in Fig. $5\left(\mathrm{c}^{\prime}\right)$, indicating the $\mathrm{C}-\mathrm{p}_{z}$ orbital and the $\mathrm{Ni}-\mathrm{d}_{z^{2}}$ orbital form covalent bonds. Above the Fermi energy, the electron occupied states of the $\mathrm{Ni}-\mathrm{d}_{z^{2}}$ orbital increase obviously. In addition, for carbon and Ni atoms near the configuration centre, a few overlapping peaks between the $\mathrm{C}-\mathrm{p}_{z}$ orbital and the Ni- $\mathrm{d}_{x^{2}-y^{2}}$ orbital in the energy range from -3 to $0 \mathrm{eV}$, which indicates the formation of covalent bonds between the $\mathrm{C}-\mathrm{p}_{z}$ orbital and the $\mathrm{Ni}-\mathrm{d}_{x^{2}-y^{2}}$ orbital. Above the Fermi energy, the electron occupied states of the $\mathrm{Ni}-\mathrm{d}_{x^{2}-y^{2}}$ orbital also increase apparently. Similar to the graphene$\mathrm{Ni}(110)$ interface, the same conclusions can also be drawn for the graphene-Co(110) interface according to the projected density of states results in Fig. 5( $\left.\mathrm{d}^{\prime}\right)$. However, when it comes to the graphene- $\mathrm{Cu}(110)$ interface, for carbon and $\mathrm{Cu}$ atoms near the configuration edge, a few overlapping peaks are found between the $\mathrm{C}-\mathrm{p}_{z}$ orbital and the $\mathrm{Cu}$-s orbital in the energy range from -5 to $-4.5 \mathrm{eV},-3$ to $-2.5 \mathrm{eV},-2$ to $-1.5 \mathrm{eV}$ and -0.5 to $0 \mathrm{eV}$ as shown in Fig. 5( $\left.\mathrm{e}^{\prime}\right)$, showing the formation of covalent bonds between the C- $\mathrm{p}_{z}$ orbital and the $\mathrm{Cu}$-s orbital. Above the Fermi energy, the electron occupied states of the $\mathrm{Cu}-\mathrm{s}$ orbital increase. Moreover, some overlapping peaks between the $\mathrm{C}-\mathrm{p}_{z}$ orbital and the $\mathrm{Cu}-\mathrm{d}_{z^{2}}$ orbital in the energy range from -5.5 to $-3.5 \mathrm{eV}$ and -3 to $-1.5 \mathrm{eV}$ as shown in Fig. $5\left(\mathrm{f}^{\prime}\right)$ indicate the $\mathrm{C}$ $\mathrm{p}_{z}$ orbital and the $\mathrm{Cu}-\mathrm{d}_{z^{2}}$ orbital form covalent bonds but the amount of overlapping peaks is less than that between the C- $\mathrm{p}_{z}$ orbital and the Ni- $\mathrm{d}_{z^{2}}$ (or Co- $\mathrm{d}_{z^{2}}$ ) orbital, illustrating the interaction between the $\mathrm{C}-\mathrm{p}_{z}$ orbital and the $\mathrm{Cu}-\mathrm{d}_{z^{2}}$ orbital is weaker.

Table 4 The bond lengths of carbon and metal atoms induced by the adsorption of graphene on the (100) surface of $\mathrm{Ni}, \mathrm{Co}$ and $\mathrm{Cu}$

\begin{tabular}{llll}
\hline$r(\AA)$ & $\mathrm{C}-\mathrm{Ni}(100)$ & $\mathrm{C}-\mathrm{Co}(100)$ & $\mathrm{C}-\mathrm{Cu}(100)$ \\
\hline$r_{1-1}$ & 3.001 & 3.164 & 3.278 \\
$r_{2-2}$ & 2.130 & 2.129 & 2.843 \\
$r_{3-3}$ & 1.970 & 1.966 & 2.321 \\
$r_{4-4}$ & 1.998 & 1.997 & 2.321 \\
$r_{5-5}$ & 1.998 & 1.997 & 2.843 \\
$r_{6-6}$ & 1.970 & 1.966 & 3.278 \\
$r_{7-7}$ & 2.130 & 2.129 & - \\
$r_{8-8}$ & 3.001 & 3.164 & -
\end{tabular}



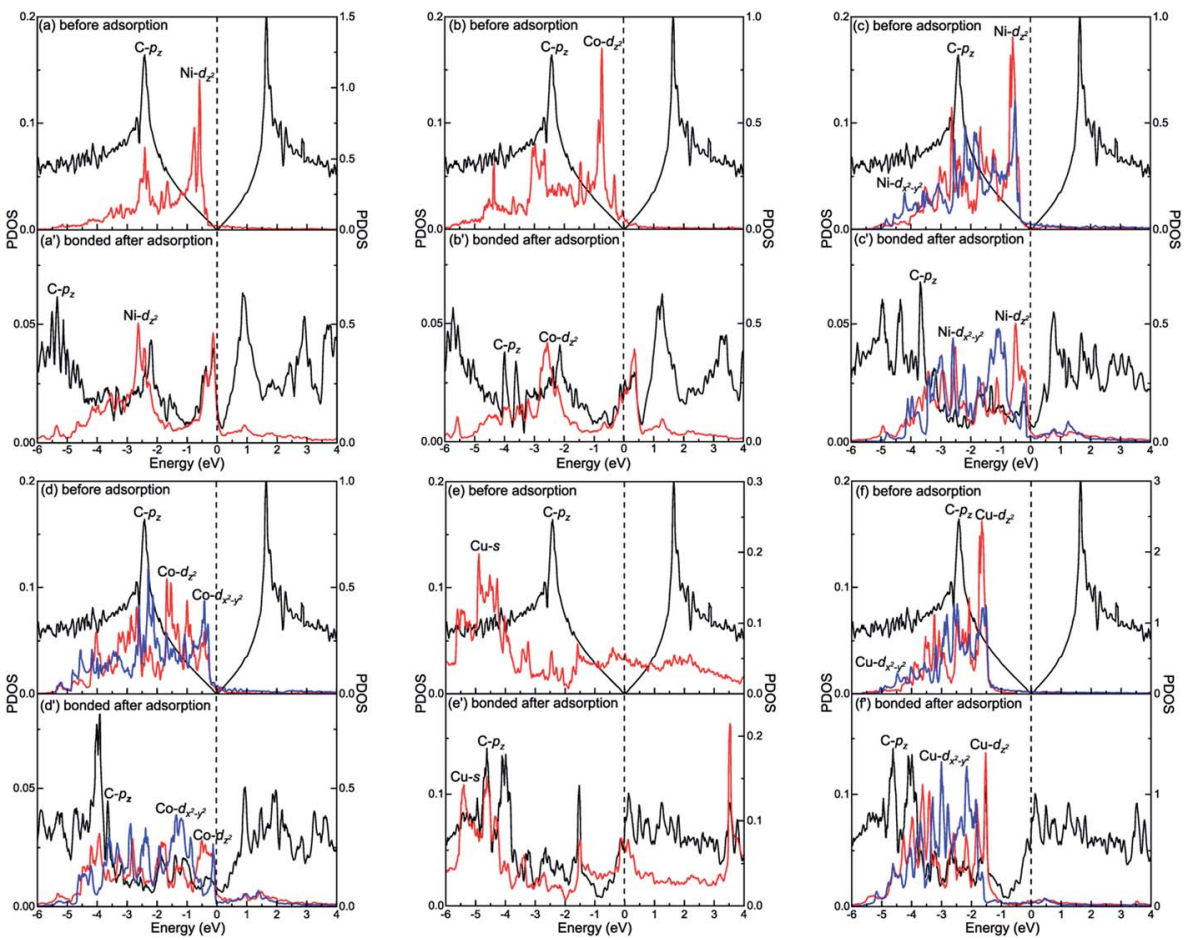

Fig. 5 The PDOS of carbon and metal atoms before and after graphene is chemisorbed on the (a and $\left.a^{\prime}\right)$ Ni(111), (b and b') Co(111), (c and $\left.c^{\prime}\right)$ $\mathrm{Ni}(110),\left(d\right.$ and $\left.d^{\prime}\right) \mathrm{Co}(110)$ and $\left(e, e^{\prime}, f\right.$ and $\left.f^{\prime}\right) \mathrm{Cu}(110)$ surfaces. Left- $Y$ represents PDOS of carbon atoms and Right- $Y$ represents PDOS of metal atoms.

Above the Fermi energy, the electron occupied states of the $\mathrm{Cu}$ $\mathrm{d}_{z^{2}}$ orbital also increase remarkably. For carbon and $\mathrm{Cu}$ atoms near the configuration centre, a few overlapping peaks are found between the $\mathrm{C}-\mathrm{p}_{z}$ orbital and the $\mathrm{Cu}-\mathrm{d}_{x^{2}-y^{2}}$ orbital as shown in Fig. $5\left(\mathrm{f}^{\prime}\right)$ in the energy range from -4.5 to $-1.5 \mathrm{eV}$, demonstrating the C- $\mathrm{p}_{z}$ orbital and the $\mathrm{Cu}-\mathrm{d}_{x^{2}-y^{2}}$ orbital form covalent bonds. What's more, the electron occupied states of the $\mathrm{Cu}-\mathrm{d}_{x^{2}-y^{2}}$ orbital also increase obviously above the Fermi energy.

However, there is no orbital coupling effect between the carbon and $\mathrm{Cu}$ atoms after graphene is adsorbed on the $\mathrm{Cu}(111)$ surface. Thus, the adsorption of graphene on the $\mathrm{Cu}(111)$ surface is only physical adsorption. More specifically, there are slight changes in the PDOS of the C- $\mathrm{p}_{z}$ orbital but the projected densities of states of the $\mathrm{Cu}$-s and $\mathrm{Cu}-\mathrm{d}_{z^{2}}$ orbitals remain almost unchanged and there are no overlapping peaks found between the $\mathrm{C}-\mathrm{p}_{z}$ orbital and the $\mathrm{Cu}-\mathrm{s}$ and $\mathrm{Cu}-\mathrm{d}_{z^{2}}$ orbitals as shown in Fig. $6\left(a^{\prime}\right)$ and $\left(b^{\prime}\right)$, which indicates the C- $\mathrm{p}_{z}$ orbital does not form covalent bonds with the $\mathrm{Cu}-\mathrm{s}$ and $\mathrm{Cu}-\mathrm{d}_{z^{2}}$ orbitals. Still, the electron occupied states of the $\mathrm{Cu}-\mathrm{s}$ and $\mathrm{Cu}-\mathrm{d}_{z^{2}}$ orbitals remain almost unchanged.

Interestingly, there exists the strong orbital coupling effect between the carbon and metal atoms in some parts of the model while there is no orbital coupling effect between the carbon and metal atoms in other parts of the model after graphene is adsorbed on the (100) surface of $\mathrm{Ni}, \mathrm{Co}$ and $\mathrm{Cu}$. Therefore, the adsorption of graphene on the (100) surface of $\mathrm{Ni}$, Co and $\mathrm{Cu}$ is all physical and chemical mixed adsorption. When it comes to the graphene-Ni(100) interface, for carbon and $\mathrm{Ni}$ atoms near the configuration centre, there are lots of overlapping peaks found between the $\mathrm{C}-\mathrm{p}_{z}$ orbital and the Ni- $\mathrm{d}_{z^{2}}$ orbital in the energy range from -5.5 to $-1.5 \mathrm{eV}$, and -0.5 to $0 \mathrm{eV}$ as shown in Fig. $7\left(\mathrm{a}^{\prime}\right)$, demonstrating the C-p $\mathrm{p}_{z}$ orbital and the Ni- $\mathrm{d}_{z^{2}}$ orbital form covalent bonds. Still, the electron occupied states of the $\mathrm{Ni}-\mathrm{d}_{z^{2}}$ orbital above the Fermi energy increase obviously. However, for carbon and $\mathrm{Ni}$ atoms near the configuration edge, there are no overlapping peaks found between the C-p $z$ orbital and the Ni- $\mathrm{d}_{z^{2}}$ orbital below the Fermi energy as shown in Fig. $7\left(\mathrm{a}^{\prime \prime}\right)$, which shows no formation of covalent bonds between the $\mathrm{C}-\mathrm{p}_{z}$ orbital and the $\mathrm{Ni}-\mathrm{d}_{z^{2}}$ orbital. Besides, the electron
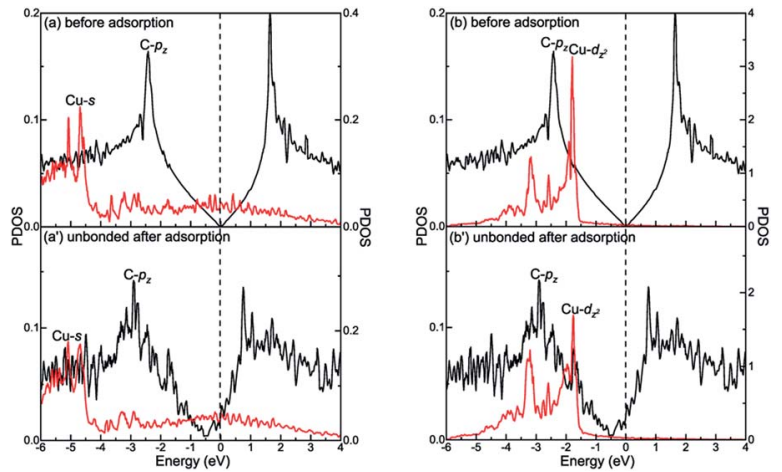

Fig. 6 The PDOS of carbon and metal atoms before and after graphene is physically adsorbed on the ( $a$ and $b)$ and $\left(a^{\prime}\right.$ and $\left.b^{\prime}\right) \mathrm{Cu}(111)$ surface. Left- $Y$ represents PDOS of carbon atoms and Right- $Y$ represents PDOS of metal atoms. 

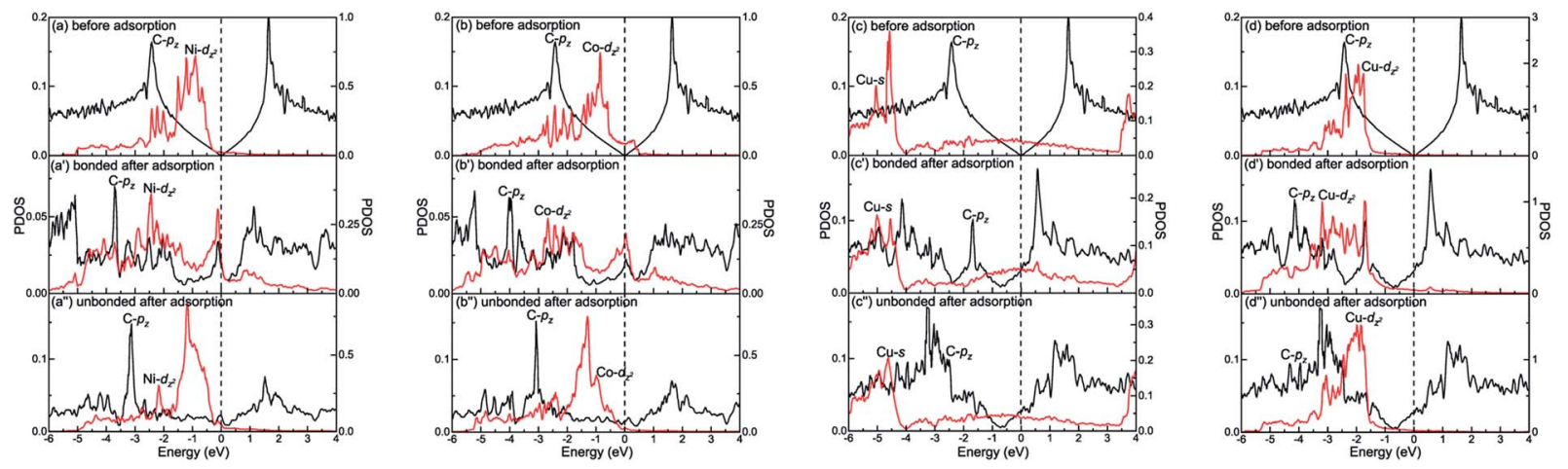

Fig. 7 The PDOS of carbon and metal atoms before and after graphene is physically and chemically mixed adsorbed on the (a, $a^{\prime}$ and $\left.a^{\prime \prime}\right)$ Ni(100), $\left(b, b^{\prime}\right.$ and $\left.b^{\prime \prime}\right) C O(100)$, and $\left(c-c^{\prime \prime}\right.$ and $\left.d-d^{\prime \prime}\right) C u(100)$ surfaces. Left- $Y$ represents PDOS of carbon atoms and Right- $Y$ represents PDOS of metal atoms.

occupied states of the Ni- $\mathrm{d}_{z^{2}}$ orbital above the Fermi energy also remain almost unchanged. Similarly, as far as the graphene$\mathrm{Co}(100)$ interface is concerned, the same conclusions can be drawn according to Fig. $7\left(b^{\prime}\right)$ and $\left(b^{\prime \prime}\right)$. However, as far as the graphene- $\mathrm{Cu}(100)$ interface is concerned, for carbon and $\mathrm{Cu}$ atoms near the configuration centre, several overlapping peaks are found between the $\mathrm{C}-\mathrm{p}_{z}$ orbital and the Cu-s orbital in the energy range from -5.5 to $-5 \mathrm{eV}$ and -2 to $-1.5 \mathrm{eV}$ as shown in Fig. $7\left(c^{\prime}\right)$, which indicates the C-p $p_{z}$ orbital and the Cu-s orbital form covalent bonds. Above the Fermi energy, the electron occupied states of the Cu-s orbital increase. What's more, the overlapping peaks between the $\mathrm{C}-\mathrm{p}_{z}$ orbital and the $\mathrm{Cu}-\mathrm{d}_{z^{2}}$ orbital mainly concentrate in the energy range from -4 to $-1 \mathrm{eV}$ as shown in Fig. $7\left(\mathrm{~d}^{\prime}\right)$, which also shows the formation of covalent bonds between the C- $\mathrm{p}_{z}$ orbital and the $\mathrm{Cu}-\mathrm{d}_{z^{2}}$ orbital. Still, the electron occupied states of the $\mathrm{Cu}-\mathrm{d}_{z^{2}}$ orbital increase apparently above the Fermi energy. It's worth noting that the amount of overlapping peaks between the C-p $\mathrm{p}_{z}$ orbital and the $\mathrm{Cu}-\mathrm{d}_{z^{2}}$ orbital is less than that of the central carbon atoms adsorbed on the $\mathrm{Ni}(100)$ and $\mathrm{Co}(100)$ surfaces, which indicates the interaction between the $\mathrm{C}-\mathrm{p}_{z}$ orbital and the $\mathrm{Cu}-\mathrm{d}_{z^{2}}$ orbital is weaker. However, for carbon and $\mathrm{Cu}$ atoms near the configuration edge, there are no overlapping peaks found between the $\mathrm{C}-\mathrm{p}_{z}$ orbital and the $\mathrm{Cu}-\mathrm{s}$ and $\mathrm{Cu}-\mathrm{d}_{z^{2}}$ orbitals as shown in Fig. $7\left(\mathrm{c}^{\prime \prime}\right)$ and $\left(\mathrm{d}^{\prime \prime}\right)$, showing the $\mathrm{C}-\mathrm{p}_{z}$ orbital does not form covalent bonds with the $\mathrm{Cu}-\mathrm{s}$ and $\mathrm{Cu}-\mathrm{d}_{z^{2}}$ orbitals. Besides, the electron occupied states of the $\mathrm{Cu}-\mathrm{s}$ and $\mathrm{Cu}-\mathrm{d}_{z^{2}}$ orbitals remain almost unchanged.

\section{Differential charge density}

The differential charge density has been calculated to further confirm the adsorption types of graphene on the metal surfaces.

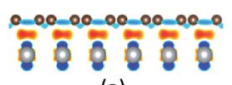

(a)

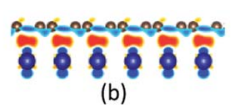

(b)

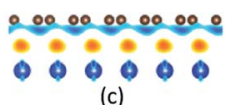

Fig. 8 The differential charge density plots induced by the adsorption of graphene on (a) Ni(111), (b) Co(111), (c) Cu(111).

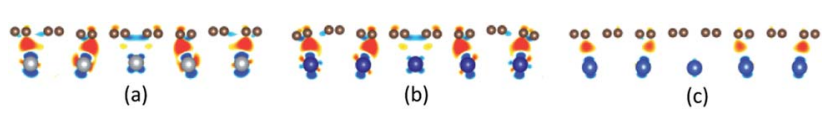

Fig. 9 The differential charge density plots induced by the adsorption of graphene on (a) $\mathrm{Ni}(110)$, (b) $\mathrm{Co}(110)$, (c) $\mathrm{Cu}(110)$.

The differential charge density plots induced by the adsorption of graphene on (111), (110) and (100) surfaces of metals are shown in Fig. 8-10, respectively. The red/blue colours mark an increase/decrease of the charge density. In addition, iso surfaces correspond to $5 \times 10^{-3} \mathrm{e}^{-3}$ and the saturation levels are from -0.01 to 0.01 e $\AA^{-3}$ for Fig. 8-10 except for Fig. 8(c). Iso surfaces correspond to $5 \times 10^{-4}$ e $\AA^{-3}$ and the saturation levels are from -0.001 to 0.001 e $\AA^{-3}$ for Fig. 8(c). In the case of the graphene-Ni(111) interface as shown in Fig. 8(a), lots of charge accumulation is found between the carbon and $\mathrm{Ni}$ atoms at the interface, which shows the carbon and $\mathrm{Ni}$ atoms form covalent bonds. In other words, the adsorption of graphene on the $\mathrm{Ni}(111)$ surface is chemisorption adsorption. For the grapheneCo(111) interface as shown in Fig. 8(b), the differential charge density result of the graphene-Co(111) interface is similar to that of the graphene-Ni(111) interface, that's to say, the adsorption of graphene on the $\mathrm{Co}(111)$ surface is also chemisorption. By contrast, there is a little charge accumulation between the carbon and $\mathrm{Cu}$ atoms at the graphene- $\mathrm{Cu}(111)$ interface after graphene is adsorbed on the $\mathrm{Cu}(111)$ surface as shown in Fig. 8(c), illustrating there are no covalent bonds between the carbon and $\mathrm{Cu}$ atoms. Therefore, the adsorption of graphene on the $\mathrm{Cu}(111)$ surface is only physical adsorption.

Notably, there are few reports about the differential charge densities after graphene is adsorbed on the (110) and (100) surfaces of metals. For the graphene-Ni(110) interface as shown

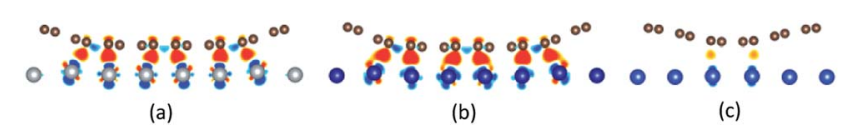

Fig. 10 The differential charge density plots induced by the adsorption of graphene on (a) Ni(100), (b) Co(100), (c) Cu(100). 
in Fig. 9(a), there exists a lot of charge accumulation between the carbon and $\mathrm{Ni}$ atoms at the interface, which confirms the carbon and Ni atoms form covalent bonds. That's to say, the adsorption of graphene on the $\mathrm{Ni}(110)$ surface is chemisorption. When it comes to the graphene-Co(110) interface as shown in Fig. 9(b), the same conclusion can be drawn that the adsorption of graphene on the $\mathrm{Co}(110)$ interface is also chemisorption. In terms of the graphene- $\mathrm{Cu}(110)$ interface as shown in Fig. 9(c), there also exists many charge accumulation between the carbon and $\mathrm{Cu}$ atoms at the interface. The result shows the carbon and $\mathrm{Cu}$ atoms also form covalent bonds, which confirms the adsorption of graphene on the $\mathrm{Cu}(110)$ surface is chemisorption but the interaction at the graphene- $\mathrm{Cu}(110)$ interface is weaker than that at the graphene-Ni(110) interface and at the graphene-Co(110) interface. Therefore, to be more accurate, the adsorption of graphene on the $\mathrm{Cu}(110)$ surface is weak chemisorption.

An interesting phenomenon is that the graphene sheet shows a large of buckling after graphene is adsorbed on the (100) surface of $\mathrm{Ni}$, Co and $\mathrm{Cu}$, which makes the interactions between the carbon and metal atoms have some differences. In terms of the graphene-Ni(100) interface as shown in Fig. 10(a), for carbon and $\mathrm{Ni}$ atoms near the configuration edge, there is almost no charge transfer found between them, illustrating the interactions between them are only van der Waals force. Therefore, the adsorption of the carbon atoms near the configuration edge on the $\mathrm{Ni}(100)$ surface is physical adsorption. However, for carbon and $\mathrm{Ni}$ atoms near the configuration centre, there is a lot of charge accumulation between them at the interface, which explains why the carbon and Ni atoms form covalent bonds. In other words, the adsorption of the carbon atoms near the configuration centre on the $\mathrm{Ni}(100)$ surface is chemisorption. Therefore, the adsorption of graphene on the $\mathrm{Ni}(100)$ surface is the coexistence of physical adsorption and chemisorption. Similar differential charge density result can be found for the graphene-Co(100) interface as shown in Fig. 10(b), that's to say, the adsorption of graphene on the $\mathrm{Co}(100)$ surface is also physical and chemical mixed adsorption. Compared with the graphene-Ni(100) interface and graphene$\mathrm{Co}(100)$ interface, for the carbon and $\mathrm{Cu}$ atoms near the configuration edge as shown in Fig. 10(c), almost no charge accumulation is found between them at the interface, which shows the carbon and $\mathrm{Cu}$ atoms don't form covalent bonds, that is, the adsorption of the carbon atoms near the configuration edge on the $\mathrm{Cu}(100)$ surface is physical adsorption. On the contrary, for carbon and $\mathrm{Cu}$ atoms near the configuration centre, charge accumulation is found at the interface, illustrating that the carbon and $\mathrm{Cu}$ atoms form covalent bonds. In other words, the adsorption of the carbon atoms near the configuration centre on the $\mathrm{Cu}(100)$ surface is chemisorption. Therefore, the adsorption of graphene on the (100) surface of $\mathrm{Ni}, \mathrm{Co}$ and $\mathrm{Cu}$ is all physical and chemical mixed adsorption.

\section{Conclusions}

We presented a first-principles investigation of the binding energy, the bond length, the projected density of states and the differential charge density of the graphene-metal interfaces. The interfaces between graphene and low-index metal surfaces such as (111), (110) and (100) surfaces are mainly discussed in this paper. We find that the graphene sheet has a different degree of buckling after graphene is adsorbed on the (110) and (100) surfaces of $\mathrm{Ni}$, Co and $\mathrm{Cu}$. The projected density of states and the differential charge density results confirm the adsorption of graphene on the Ni(111), Co(111), Ni(110), Co(110) and $\mathrm{Cu}(110)$ surfaces is chemisorption due to the strong orbital coupling effect and the obvious charge accumulation between the carbon and metal atoms, while the adsorption of graphene on the $\mathrm{Cu}(111)$ surface is physical adsorption owing to the absence of the orbital coupling effect and the charge accumulation between the carbon and $\mathrm{Cu}$ atoms. Interestingly, the adsorption of graphene on the (100) surface of $\mathrm{Ni}$, Co and $\mathrm{Cu}$ is all physical and chemical mixed adsorption because there are the strong orbital coupling effect and the apparent charge accumulation between the carbon and metal atoms in some parts of these surfaces while there are almost no orbital coupling effect and charge accumulation between the carbon and metal atoms in the other parts. The results obtained by the present study are not only expected to explain the adsorption mechanism of graphene on the metal surfaces, but also to provide help for the research of graphene-based composites and carbon nanomaterials.

\section{Conflicts of interest}

There are no conflicts to declare.

\section{Acknowledgements}

This work was supported by the CAS Frontier Science Research Project (No. QYZDJ-SSW-JSC015) and the National Key R\&D Program of China (No. 2016YFB0701302). The Special Program for Applied Research on Super Computation of the NSFCGuangdong Joint Fund (the second phase) are also highly acknowledged. Some of the calculations in this study were done on Tianhe-II high performance computer system in the National Supercomputer Centre in Guangzhou, China.

\section{References}

1 K. S. Novoselov, A. K. Geim, S. V. Morozov, D. Jiang, Y. Zhang, S. V. Dubonos, I. V. Grigorieva and A. A. Firsov, Science, 2004, 306, 666-669.

2 K. S. Novoselov, A. K. Geim, S. V. Morozov, D. Jiang, M. I. Katsnelson, I. V. Grigorieva, S. V. Dubonos and A. A. Firsov, Nature, 2005, 438, 197-200.

3 M. D. Stoller, S. Park, Y. W. Zhu, J. An and R. S. Ruoff, Nano Lett., 2008, 8, 3498-3502.

4 A. S. Mayorov, R. V. Gorbachev, S. V. Morozov, L. Britnell, R. Jalil, L. A. Ponomarenko, P. Blake, K. S. Novoselov, K. Watanabe, T. Taniguchi and A. K. Geim, Nano Lett., 2011, 11, 2396-2399.

5 C. G. Lee, X. D. Wei, J. W. Kysar and J. Hone, Science, 2008, 321, 385-388. 
6 A. A. Balandin, Nat. Mater., 2011, 10, 569-581.

7 D. L. Nika, E. P. Pokatilov, A. S. Askerov and A. A. Balandin, Phys. Rev. B: Condens. Matter Mater. Phys., 2009, 79, 155413.

8 J. Moser, A. Barreiro and A. Bachtold, Appl. Phys. Lett., 2007, 91, 163513.

9 S. Stankovich, D. A. Dikin, G. H. B. Dommett, K. M. Kohlhaas, E. J. Zimney, E. A. Stach, R. D. Piner, S. T. Nguyen and R. S. Ruoff, Nature, 2006, 442, 282-286.

10 G. M. Scheuermann, L. Rumi, P. Steurer, W. Bannwarth and R. Mülhaupt, J. Am. Chem. Soc., 2009, 131, 8262-8270.

11 H. M. A. Hassan, V. Abdelsayed, A. E. R. S. Khder, K. M. AbouZeid, J. Terner, M. S. El-Shall, S. I. Al-Resayes and A. E. El-Azhary, J. Mater. Chem., 2009, 19, 3832-3837.

12 R. Awasthi and R. N. Singh, Carbon, 2013, 51, 282-289.

13 W. J. Hong, H. Bai, Y. X. Xu, Z. Y. Yao, Z. Z. Gu and G. Q. Shi, J. Phys. Chem. C, 2010, 114, 1822-1826.

14 J. Luo, S. S. Jiang, H. Y. Zhang, J. Q. Jiang and X. Y. Liu, Anal. Chim. Acta, 2012, 709, 47-53.

15 W. H. Yuan, Y. J. Gu and L. Li, Appl. Surf. Sci., 2012, 261, 753758.

16 X. Liu, X. W. Zhang, J. H. Meng, H. L. Wang, Z. G. Yin, J. L. Wu and H. L. Gao, Nanotechnology, 2014, 25, 365602.

17 M. Bastwros, G. Y. Kim, C. Zhu, K. Zhang, S. R. Wang, X. D. Tang and X. W. Wang, Composites, Part B, 2014, 60, 111-118.

18 C. H. Jeon, Y. H. Jeong, J. J. Seo, H. N. Tien, S. T. Hong, Y. J. Yum, S. H. Hur and K. J. Lee, Int. J. Precis. Eng. Manuf., 2014, 15, 1235-1239.

19 J. Y. Wang, Z. Q. Li, G. L. Fan, H. H. Pan, Z. X. Chen and D. Zhang, Scr. Mater., 2012, 66, 594-597.

20 A. B. Preobrajenski, M. L. Ng, A. S. Vinogradov and N. Mårtensson, Phys. Rev. B: Condens. Matter Mater. Phys., 2008, 78, 073401.

21 S. Y. Kwon, C. V. Ciobanu, V. Petrova, V. B. Shenoy, J. Bareño, V. Gambin, I. Petrov and S. Kodambaka, Nano Lett., 2009, 9, 3985-3990.

22 J. Coraux, A. T. N'Diaye, C. Busse and T. Michely, Nano Lett., 2008, 8, 565-570.

23 P. Sutter, J. T. Sadowski and E. Sutter, Phys. Rev. B: Condens. Matter Mater. Phys., 2009, 80, 245411.

24 K. S. Kim, Y. Zhao, H. Jang, S. Y. Lee, J. M. Kim, K. S. Kim, J. H. Ahn, P. Kim, J. Y. Choi and B. H. Hong, Nature, 2009, 457, 706-710.

25 Y. S. Dedkov, M. Fonin, U. Rüdiger and C. Laubschat, Appl. Phys. Lett., 2008, 93, 022509.

26 M. Fuentes-Cabrera, M. I. Baskes, A. V. Melechko and M. L. Simpson, Phys. Rev. B: Condens. Matter Mater. Phys., 2008, 77, 035405.

27 P. A. Khomyakov, G. Giovannetti, P. C. Rusu, G. Brocks, J. van den Brink and P. J. Kelly, Phys. Rev. B: Condens. Matter Mater. Phys., 2009, 79, 195425.

28 F. Mittendorfer, A. Garhofer, J. Redinger, J. Klimes, J. Harl and G. Kresse, Phys. Rev. B: Condens. Matter Mater. Phys., 2011, 84, 201401(R).
29 S. M. Kozlov, F. Viñes and A. Görling, J. Phys. Chem. C, 2012, 116, 7360-7366.

30 X. Sun, S. Entani, Y. Yamauchi, A. Pratt and M. Kurahashi, J. Appl. Phys., 2013, 114, 143713.

31 T. Abtew, B. C. Shih, S. Banerjee and P. H. Zhang, Nanoscale, 2013, 5, 1902-1909.

32 W. B. Zhang, C. Chen and P. Y. Tang, J. Chem. Phys., 2014, 141, 044708.

33 F. Bianchini, L. L. Patera, M. Peressi, C. Africh and G. Comelli, J. Phys. Chem. Lett., 2014, 5, 467-473.

34 L. Gao, Y. Liu, T. B. Ma, R. Y. Shi, Y. Z. Hu and J. B. Luo, Appl. Phys. Lett., 2016, 108, 261601.

35 B. R. Didar and P. B. Balbuena, Langmuir, 2018, 34, 13111320.

36 A. Grüneis and D. V. Vyalikh, Phys. Rev. B: Condens. Matter Mater. Phys., 2008, 77, 193401.

37 B. Wang, M. Caffio, C. Bromley, H. Früchtl and R. Schaub, ACS Nano, 2010, 4, 5773-5782.

38 X. S. Li, W. W. Cai, J. H. An, S. Kim, J. Nah, D. X. Yang, R. Piner, A. Velamakanni, I. Jung, E. Tutuc, S. K. Banerjee, L. Colombo and R. S. Ruoff, Science, 2009, 5, 1312-1313.

39 B. Borca, S. Barja, M. Garnica, M. Minniti, A. Politano, J. M. Rodriguez-García, J. J. Hinarejos, D. Farías, A. L. Vázquez de Parga and R. Miranda, New J. Phys., 2010, 12, 093018.

40 C. F. McConville, D. P. Woodruff and S. D. Kevan, Surf. Sci., 1986, 171, L447-L453.

41 D. G. Castner, B. A. Sexton and G. A. Somorjai, Surf. Sci., 1978, 71, 519-540.

42 J. W. May, Surf. Sci., 1969, 18, 431.

43 D. L. Mafra, J. A. Olmos-Asar, F. R. Negreiros, A. Reina, K. K. Kim, M. S. Dresselhaus, J. Kong, G. J. Mankey and P. T. Araujo, Phys. Rev. Mater., 2018, 2, 073404.

44 G. Kresse and J. Furthmüller, Phys. Rev. B: Condens. Matter Mater. Phys., 1996, 54, 11169.

45 G. Kresse and J. Furthmüller, Comput. Mater. Sci., 1996, 6, 15-50.

46 J. P. Perdew and A. Zunger, Phys. Rev. B: Condens. Matter Mater. Phys., 1981, 23, 5048-5079.

47 M. Vanin, J. J. Mortensen, A. K. Kelkkanen, J. M. GarciaLastra, K. S. Thygesen and K. W. Jacobsen, Phys. Rev. B: Condens. Matter Mater. Phys., 2010, 81, 081408(R).

48 P. E. Blöchl, O. Jepsen and O. K. Andersen, Phys. Rev. B: Condens. Matter Mater. Phys., 1994, 49, 16223-16233.

49 G. Kresse and D. Joubert, Phys. Rev. B: Condens. Matter Mater. Phys., 1999, 59, 1758-1775.

50 M. Corso, W. Auwärter, M. Muntwiler, A. Tamai, T. Greber and J. Osterwalder, Science, 2004, 303, 217-220.

51 J. Wollschläger, D. Erdös, H. Goldbach, R. Höpken and K. M. Schröder, Thin Solid Films, 2001, 400, 1-8.

52 J. Neugebauer and M. Scheffler, Phys. Rev. B: Condens. Matter Mater. Phys., 1992, 46, 16067-16080.

53 C. Gong, G. Lee, B. Shan, E. M. Vogel, R. M. Wallace and K. Cho, J. Appl. Phys., 2010, 108, 123711. 